\title{
ESSENTIAL AMINO ACID METHYL ESTERS: MAJOR SEX PHEROMONE COMPONENTS OF THE CRANBERRY WHITE GRUB, Phyllophaga anxia (COLEOPTERA: SCARABAEIDAE)
}

\author{
AIJUN ZHANG,* PAUL S. ROBBINS, WALTER S. LEAL, $\dagger$ \\ CHARLES E. LINN, JR., MICHAEL G. VILLANI, and \\ WENDELL L. ROELOFS \\ Department of Entomology \\ NYS Agriculture Experiment Station \\ Cornell University \\ Geneva, New York 14456
}

(Received April 9, 1996; accepted August 30, 1996)

\begin{abstract}
Chiral capillary gas chromatographic-electroantennographic detection (GC-EAD) analysis indicates that $L$-valine and $L$-isoleucine methyl esters are the major sex pheromone components released by females of the cranberry white grub, Phyllophaga anxia (LeConte). The GC retention times and GCmass spectrometry of the two natural compounds were identical to those of authentic standards. Of five reproducible GC-EAD active components revealed with female volatiles, the L-valine and L-isoleucine methyl esters elicited the strongest male antennal responses. The ratio of $\mathrm{L}$-valine and $\mathrm{L}$-isoleucine methyl esters was determined to be $3: 1$ by analysis of pheromone gland extracts. Chirality was shown to be critical by GC-EAD, since only the L-form of these amino acid methyl esters elicited an EAD response. In field experiments conducted in Massachusetts, a synthetic 3:1 blend of L-valine and L-isoleucine methyl esters on a rubber septum was attractive to $P$. anxia males.
\end{abstract}

Key Words-Phyllophaga anxia, Coleoptera, Scarabaeidae, cranberry white grub, sex pheromone, chirality, L-valine methyl ester, L-isoleucine methyl ester, electroantennographic detection, field trapping.

*To whom correspondence should be addressed.

†Current address: National Institute of Sericultural and Entomological Science, Tsukuba 305, Japan. 
INTRODUCTION

The cranberry white grub, Phyllophaga anxia, belongs to the family Scarabaeidae, subfamily Melolonthinae, tribe Melonothini. There is a total of 200 species of Phyllophaga widely distributed over the world (Westcott, 1964). About 152 species are native to North America (Tashiro, 1987). Larvae of the genus Phyllophaga are commonly known as white grubs due to their body color (Ritcher, 1966), whereas adults are referred to as May or June beetles due to their flight period. Several species of Phyllophaga are identified as major agricultural pests, and in the northeastem United States and Canada $P$. anxia has been recognized as the most widespread and injurious species (Tashiro, 1987). Damage is caused by larvae feeding on the roots and underground plant parts. They may eventually kill the host plants, which include forest trees, tree nursery seedbeds, strawberry, cranberry, roses, corn, and turfgrass (Metcalf et al., 1951; Westcott, 1964). Because the larvae are aggressive feeders and reach a relatively large size as third instars $(25-38 \mathrm{~mm})$, only a few grubs per unit area can be very damaging (Tashiro, 1987). Although insecticides have been used for larval control of Phyllophaga (Franklin, 1950; Metcalf et al., 1951), larval injury is still a serious problem.

Although about 950 insect pheromones and sex attractants have been listed for more than 1300 insect species by the early years of this decade (Mayer and McLaughlin, 1991), chemical communication in the Phyllophaga has not been reported until now. To aid in the detection and management of $P$. anxia in cranberry, we initiated a study to determine if a sex pheromone is used for mate location. In a preliminary test, we found that female $P$. anxia volatiles elicited male activity. Males were active in the flight tunnel, but none took flight to either the airborne collection or a female source. In an additional study, we discovered that the female volatiles elicited significant male EAG responses and that the active materials could be separated into several fractions by capillary gas chromatography. Here we report the identification of two pheromone components, methyl esters of the essential amino acids, L-valine and L-isoleucine.

\section{METHODS AND MATERIALS}

Insects. Cranberry white grub adults and larvae used in these studies were collected from Cranebrook cranberry bog near Wareham, Massachusetts, in the spring and fall of 1994. The individuals used in the preliminary investigations of summer 1994 were collected in early May of that year, while those used in the spring of 1995 were collected in October and overwintered at $10^{\circ} \mathrm{C}$ until early March, at which time the females were ready to emerge from the soil and 
produce pheromone in scotophase. Insects were stored in soil-filled $\sim 30-\mathrm{ml}$ disposable plastic cups.

Pheromone Collections. Two female beetles were introduced each time into an airborne collection apparatus, consisting of one three-neck glass bottle $(500 \mathrm{ml})$ connected to a Super Q $(200 \mathrm{mg}$; Alttech Associates, Inc., Deerfield, IL) trap $(15 \mathrm{~cm} \times 0.6-\mathrm{cm} \mathrm{OD)}$. The air was filtered with a charcoal (activated carbon, 6-14 mesh; Fisher Scientific) trap (7 cm $\times 1-\mathrm{cm} \mathrm{OD)} \mathrm{and} \mathrm{then} \mathrm{passed}$ through a humidifying bubbler tube before being pulled through the apparatus with a vacuum pump at $\sim 1 \mathrm{liter} / \mathrm{min}$. Female beetles were aerated continuously for $8 \mathrm{hr}$ each day, from 0830 to 1630 in scotophase. The beetles were kept on a diel cycle of $16 \mathrm{hr}$ in photophase at $27^{\circ} \mathrm{C}$ and $8 \mathrm{hr}$ in scotophase at $18.5^{\circ} \mathrm{C}$. The Super $Q$ traps were changed every day. The airborne volatiles were eluted from the Super $Q$ trap with four portions of glass-distilled hexane $(0.5 \mathrm{ml} / \mathrm{each})$. The resultant hexane solutions were combined and concentrated under a stream of nitrogen to a volume of about $100 \mu \mathrm{l}$. The concentrated extracts were used directly for GC-EAD or fractionation on the capillary GC.

Female Gland Extracts. Gland extracts were obtained by compressing the abdomen of the females until the pheromone gland everted from the abdominal tip. Two excised glands were soaked in $200 \mu 1$ methylene chloride for $20 \mathrm{~min}$. Extracts were combined and concentrated to a small volume (about $100 \mu \mathrm{l}$ ) in a nitrogen stream.

Instrumentation. Fractionation and purification of the active components were performed on a Hewlett Packard 5880A gas chromatograph equipped with a nonpolar SE-30 Econo-Cap capillary column $(30 \mathrm{~m} \times 0.25-\mathrm{mm} \mathrm{ID,} 0.25-\mu \mathrm{m}$ film thickness; Alltech Associates, Inc., Deerfield, IL) in the splitless mode. The oven temperature was programmed at $40^{\circ} \mathrm{C}$ for $5 \mathrm{~min}$, then increased at $10^{\circ} \mathrm{C} / \mathrm{min}$ to $200^{\circ} \mathrm{C}$ and held for $20 \mathrm{~min}$. Injector and detector temperatures were set at $220^{\circ} \mathrm{C}$. Nitrogen was the carrier gas, with the flow rate at $2 \mathrm{ml} /$ $\mathrm{min}$. Septum purge flow rate was set at $3 \mathrm{ml} / \mathrm{min}$ and split vent flow rate at 2 $\mathrm{ml} / \mathrm{min}$, respectively. All of the gas source pressures were $276 \mathrm{kPa}(40 \mathrm{psi})$ and initial column head pressures were $138 \mathrm{kPa}(20 \mathrm{psi})$. Fractions eluting from the column were collected each minute in Dry Ice-chilled 75- $\mu$ l micropipets (VWR Scientific Inc., Philadelphia, PA), which were cleaned by heating to $550^{\circ} \mathrm{C}$ in a muffle oven for $12 \mathrm{hr}$. Each micropipet was rinsed with a total of $100 \mu \mathrm{l}$ of glass-distilled hexane to remove trapped fractions.

GC-mass spectrometry (GC-MS) was carried out with a Hewlett Packard 5890 gas chromatograph coupled to a HP 5970B Mass Selective Detector or a Finnigan ion-trap detector (ITD 800) using the same SE-30 capillary column and conditions as above, but with helium as the carrier gas.

Electrophysiological Recordings. Pheromone samples were also subjected to GC-EAD analysis using a HP 5880A gas chromatograph equipped with a 
HP-5 capillary column $(30 \mathrm{~m} \times 0.25-\mathrm{mm}$ ID, $0.25-\mu \mathrm{m}$ film thickness; Hewlett Packard, Wilmington, DE). The oven temperature was programmed at $50^{\circ} \mathrm{C}$ for $1 \mathrm{~min}$, then increased at $15^{\circ} \mathrm{C} / \mathrm{min}$ to $250^{\circ} \mathrm{C}$ and held for $25 \mathrm{~min}$. A $\beta$-DEX 120 fused silica chiral capillary column $(30 \mathrm{~m} \times 0.25-\mathrm{mm}$ ID, $0.25-\mu \mathrm{m}$ film thickness; Supelco, Inc., Bellefonte, PA) was used for chirality analysis. The oven temperature was programmed at $80^{\circ} \mathrm{C}$ for $2 \mathrm{~min}$, then raised at $1{ }^{\circ} \mathrm{C} / \mathrm{min}$ to $220^{\circ} \mathrm{C}$ and held for $25 \mathrm{~min}$. The capillary column effluent and nitrogen makeup gas $(30 \mathrm{ml} / \mathrm{min})$ were split (ca. 1:1) by a Y GlasSeal capillary column connector (Supelco, Inc.) to a flame ionization detector (FID) and an electroantennographic detector (EAD). After one antenna was removed from the beetle, one lamella tip and scape were mounted on an acrylic holding station (Leal et al., 1992) with the club open. Two pure gold wires and isotonic saline solution $(0.9 \% \mathrm{NaCl})$ were used in all experiments. The output recording electrodes were connected by a short coaxial cable to a high-impedance $1: 100$ amplifier (Bjostad and Roelofs, 1980) with automatic baseline drift compensation. The airstream flowing over the antenna (about $500 \mathrm{ml} / \mathrm{min}$ ) was humidified by bubbling through distilled water before entering the EAD interface. The temperature of the antenna on the acrylic station was maintained at about $16^{\circ} \mathrm{C}$ by pumping $10^{\circ} \mathrm{C}$ ice-cooled water into the insulated layer of the modified condenser containing the acrylic station mounted on the top of GC apparatus. An HP 3390 A integrator was used for EAD recording.

The EAG responses of male antennae were obtained using $\mathrm{Ag}-\mathrm{AgCl}$ glass electrodes (Roelofs, 1984) filled with isotonic saline solution $(0.9 \% \mathrm{NaCl})$, and they were displayed on a Tektronix 2212 digital storage and analog oscilloscope and printed by a Tektronix HC 200 nine-pin dot-matrix tekprinter. The same high-input impedance DC amplifier (Bjostad and Roelofs, 1980) used in GCEAD was employed in EAG.

Chemicals. The conversion of individual amino acids into their methyl esters was achieved by the modified method of Brenner (Brenner and Huber, 1953). The esterification reaction proceeded with a $1.2 \mathrm{~mol}$ ratio of thionyl chloride, with cooling at $-4^{\circ} \mathrm{C}$ provided by an ice bath. Thionyl chloride (8.8 $\mathrm{ml}, 120 \mathrm{mmol}$ ) was slowly added to $30.0 \mathrm{ml}$ of anhydrous methyl alcohol cooled with an ice bath. After the addition was completed, isoleucine $(13.1 \mathrm{~g}, 100$ mmol) or valine $(11.7 \mathrm{~g}, 100 \mathrm{mmol})$ was slowly added in portions with vigorous stirring at $0^{\circ} \mathrm{C}$. The resulting mixture was stirred at $0^{\circ} \mathrm{C}$ for $0.5 \mathrm{hr}$, then warmed to $40^{\circ} \mathrm{C}$ and maintained at this temperature while being stirred for another $2 \mathrm{hr}$. The methyl alcohol was removed in vacuo, and the residue diluted with $10 \mathrm{ml}$ of water. The reaction mixture was treated with concentrated ammonium hydroxide until the water layer was basic to litmus, then extracted with three portions of ether $(100 \mathrm{ml} / \mathrm{each})$. The organic layer was combined, washed with brine, dried over sodium sulfate, and concentrated in vacuo. The residue was purified by distillation to give pure products in a $70-90 \%$ yield. L-Valine (Grand 
Island Biological Company, Grand Island, NY) methyl ester was obtained at $80^{\circ} \mathrm{C}$ under $15 \mathrm{~mm} \mathrm{Hg}$ and $\mathrm{L}$-isoleucine (Grand Island Biological Company) methyl ester was obtained at $98^{\circ} \mathrm{C}$ under $15 \mathrm{~mm} \mathrm{Hg}$. The unnatural amino acid (D-valine and D-isoleucine from Aldrich Chemical Company, Inc., Milwaukee, WI; D-allo- and L-allo-isoleucine from Sigma Chemical Co., St. Louis, MO) methyl esters were prepared in small amounts in vials stored at $40^{\circ} \mathrm{C}$ for $4 \mathrm{hr}$ without stirring, and no distillation was performed. The isomeric purity of all isomers was $>90 \%$ based on results with the capillary GC (FID). The mixtures of DL-isoleucine purchased from either Aldrich or Sigma actually were a mixture of 1:1 D-allo- and L-isoleucine, which was determined and confirmed by chromatography of their methyl esters on the chiral capillary column.

Field Tests. Field tests were conducted in two cranberry white grub infested bogs in Massachusetts during the 1995 field season. Four Fuji Flavor wing-type traps (Fuji Flavor Co., Ltd., 3-5-8 Midorigaoka, Hamura-Shi, Tokyo 205, Japan) baited with septa containing $0,1,3$, or $10 \mathrm{mg}$ synthetic pheromone were placed $20 \mathrm{~m}$ apart in a line on the edge of each of the two bogs. Traps were hung 1 $\mathrm{m}$ high on metal stakes. Trapped beetles were removed twice each week from May 15 until July 14. Traps were rotated once each week when the septa were changed.

\section{RESULTS}

Identification of the Major Sex Pheromone Component. Although male $P$. anxia did not fly to the pheromone source in the flight tunnel, the airborne extract elicited the same behavioral responses as the presence of females in a screened cage at the upwind end of the tunnel. The excited males stood on their hindlegs with their prothoracic legs waving while keeping the lamellae of their antennae open. They also walked upwind with their elytra partly open. The males did not exhibit these behavioral responses to a blank control (hexane) under the same conditions. The activity of airborne extract was further demonstrated in EAG experiments. One female equivalent of collected pheromone elicited about a 4-mV EAG response with a male antenna, whereas the control (hexane alone) produced a response of less than $1 \mathrm{mV}$. The airbome extract did not elicit any significant response from female antennae under the same conditions. This suggests that the electrophysiologically active materials are sex specific and probably involved in the mating communication system.

Purification of the pheromone was carried out on a capillary GC and activity monitored by EAG. After the crude hexane extract had been concentrated by a nitrogen stream, it was applied to a nonpolar SE-30 capillary column and fractions were collected each minute. The EAG consistently revealed significant activity in five fractions (9-10, 11-12, 19-20, 21-22, and 23-24 min). These retention times correspond to the following hydrocarbon standards under the 
same conditions: nonane ( $8.50 \mathrm{~min})$, decane (10.95 $\mathrm{min})$, undecane $(12.98 \mathrm{~min})$, pentadecane (19.12 min), heptadecane $(21.65 \mathrm{~min})$, and octadecane $(23.09 \mathrm{~min})$. Further purification of each active fraction on a polar Carbowax capillary column failed, however, possibly due to the small amount of material.

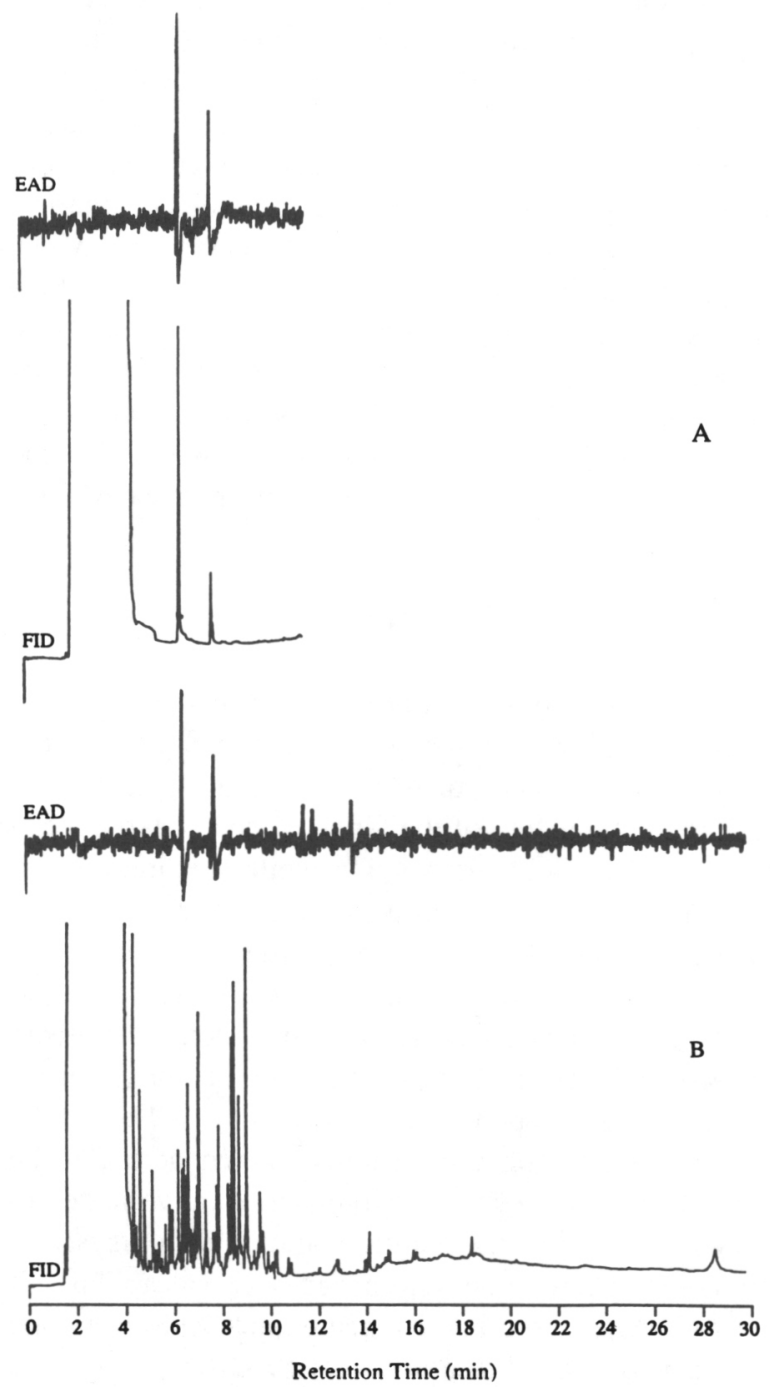

FIG. 1. Reconstructed simultaneous responses of flame ionization detection (FID) and electroanntennographic detection (EAD; antenna of male $P$. anxia) to a mixture of synthetic 3:1 L-valine and L-isoleucine methyl esters (A) and volatiles of female $P$. anxia (B) on a HP-5 capillary column. 
Crude airborne extracts were subjected to GC-EAD analysis. Five EADactive compounds $\left(t_{\mathrm{R}}=6.27,7.66,11.54,11.96\right.$, and $\left.13.48 \mathrm{~min}\right)$ were revealed on a nonpolar HP-5 capillary column (Figure 1B), which were consistent with the GC fractionation studies. However, the ratio of these active peaks could not be determined due to the complexity of the gas chromatographic record and the trace amount of materials. EAD responses to the female-gland methylene chloride extract were obtained only for the two components at the same retention times as the airborne collection at 6.27 and $7.66 \mathrm{~min}$, respectively, and the ratio of the GC peaks was clearly demonstrated as $3: 1$.

The MS spectrum of the active component corresponding to the first EAD response $\left(t_{\mathrm{R}}=6.27 \mathrm{~min}\right)$ exhibited a small ion at $\mathrm{m} / \mathrm{z} 131(0.2)$ along with the following fragments: $41(8), 55(46), 72(100)$, and $88(30)$. The fragment at $\mathrm{m} / \mathrm{z} 131$ appeared to represent the molecular ion because all fragments at lower mass were chemically reasonable mass differences relative to this signal. This assumption was confirmed by a Finnigan ion-trap detector (ITD 800), in which self-ionization gave rise to the $\mathrm{M}+1$ peak $(\mathrm{m} / \mathrm{z}, 132)$ as the highest mass unit. The odd mass value indicated the presence of an odd number of nitrogen atoms in the molecular formula (nitrogen rule). Since there was no evidence for the presence of other heteroatoms and no reason for assuming the presence of three nitrogen atoms in such a small molecule, the most likely molecular formulae were $\mathrm{C}_{4} \mathrm{H}_{5} \mathrm{NO}_{4}, \mathrm{C}_{5} \mathrm{H}_{9} \mathrm{NO}_{3}$, and $\mathrm{C}_{6} \mathrm{H}_{13} \mathrm{NO}_{2}$. The fragment at $\mathrm{m} / 288\left(\mathrm{M}^{+}-43\right)$ probably represented loss of $\mathrm{C}_{3} \mathrm{H}_{7}$ or $\mathrm{CH}_{3} \mathrm{CO}$. With a base peak at $\mathrm{m} / z \mathbf{7 2}\left(\mathrm{M}^{+}\right.$59), the cleavage of $\mathrm{CO}_{2} \mathrm{CH}_{3}$ from the molecule probably occurred. Based on the above information, the compound was likely to be an amino acid ester. At this point, we tentatively refined our molecular formula to $\mathrm{C}_{6} \mathrm{H}_{13} \mathrm{NO}_{2}$, and proposed the structure to be valine methyl ester.

The cleavage of one of the carbon-carbon bonds next to the amino group was a very prominent fragmentation reaction in all amino acid esters (Scheme 1). The formation of immonium ions is the driving force in this fragmentation.

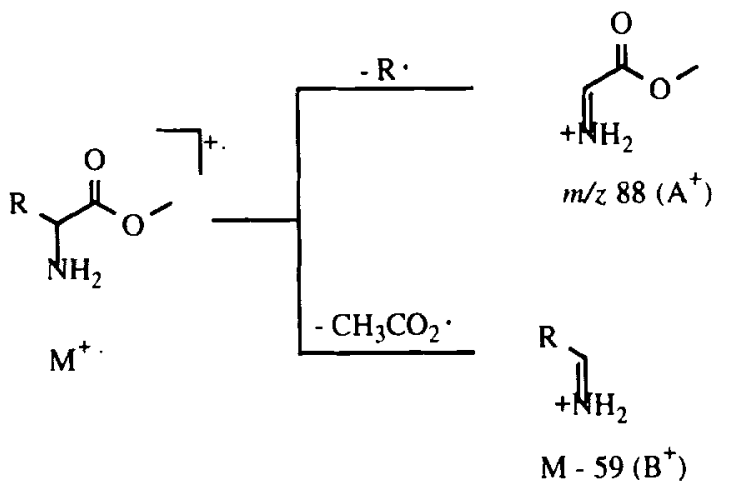

SCHEME 1. Degradation pathway of the amino acid methyl ester. 
The stability of such ions is so high that the abundance of the molecular ions usually is quite low. Of the two possible pathways, the one in which the carboxyl group is lost is more predominant than the cleavage of group $\mathrm{R}$ leading to ion $\mathbf{A}^{+}(m / z 88)$ and gives rise to the $\mathrm{M}-59$ base peak ion $\mathbf{B}^{+}(m / 272)$. The reason is that the immonium ion $\mathrm{A}^{+}$formed during fragmentation is slightly destabilized by the negative inductive effect of a conjunctive carboxyl group and thus gives rise to a lower abundance than ion $\mathrm{B}^{+}$.

This characteristic fragmentation was clearly shown in the spectrum of the first EAD active peak $\left(t_{\mathrm{R}}=6.27 \mathrm{~min}\right)$. The ion $\mathrm{B}^{+}(\mathrm{m} / z$ 72) corresponding to loss of 59 mass units from molecular $m / z, 131$ was the base peak. The ion $\mathrm{A}^{+}$ $(\mathrm{m} / \mathrm{z}, 88)$ attributed to another primary cleavage was a prominent peak with abundance at about $30 \%$. These data supported our proposal of valine methyl ester as the active component at $6.27 \mathrm{~min}$.

An identical fragmentation pattern was observed in the MS spectrum of the second EAG-active component $\left(t_{\mathrm{R}}=7.66 \mathrm{~min}\right)$. The following fragments were detected: 41 (23), 44 (22), 56 (15), 57 (17), 69 (15), 74 (14), 86 (100), 88 $(40), 116(0.3), 130(0.1)$, and $145(0.1)$. It was observed that both the base peak $\mathrm{B}^{+}(\mathrm{m} / \mathrm{z} 86)$ and the highest mass unit $(\mathrm{m} / \mathrm{z} 145)$ were 14 units higher than those for the first EAD-active peak $\left(t_{\mathrm{R}}=6.27\right)$, and the $\mathrm{A}^{+}$ion $(\mathrm{m} / z$ 88) was also found as a prominent peak. The $\mathrm{M}+1$ peak $(\mathrm{m} / z \mathrm{146})$ was the highest mass unit detected by a Finnigan ion-trap detector (ITD 800), indicating that $\mathrm{m} / z 145$ was the molecular ion. All of these data suggested that this compound is an amino acid methyl ester that possesses one more methylene unit in the $R$ group than the valine methyl ester. Three structural possibilities existed; the $\mathbf{R}$ group could be butyl, isobutyl, or sec-butyl. Thus, norleucine, leucine, and isoleucine methyl esters were candidates.

To distinguish among these possibilities and verify that the first EAD-active component was valine methyl ester, authentic standards were synthesized. Isomers such as norleucine, leucine, and isoleucine methyl esters were readily distinguished by comparing their GC retention times and MS spectra. Only synthetic L-valine and L-isoleucine methyl esters had retention times $\left(t_{\mathrm{R}}=6.27\right.$ and $7.66 \mathrm{~min}$ ) and MS spectra that were identical to those of the first and second EAD-active components produced by female $P$. anxia. A synthetic $3: 1$ blend of L-valine and L-isoleucine methyl esters also elicited the same male antenna EAD responses as the airborne collection (Figure $1 \mathrm{~A}$ ). Thus, valine and isoleucine methyl esters at a 3:1 ratio were identified as the major electrophysiologically active components of $P$. anxia. This synthetic blend was used for the remaining experiments.

Chiral Specificity Characterization. Valine methyl ester has one chiral center, and two enantiomeric forms are possible, L-valine and D-valine methyl esters. The isoleucine methyl ester, however, has two chiral centers, and two pairs of enantiomeric forms are possible, L- and D-isoleucine methyl esters and 


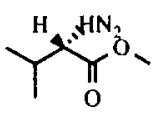

L-

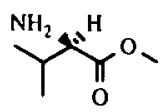

D-

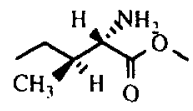

L-

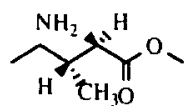

D-

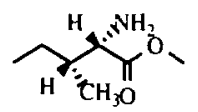

L-allo

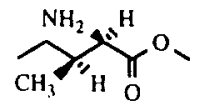

D-allo

SCHEME 2. Stereoisomers used to characterize the specificity of male $P$. anxia antennae. Top: Valine methyl esters. Bottom: Isoleucine methyl esters.

L-allo- and D-allo-isoleucine methyl esters (Scheme 2). The L-forms are the naturally occurring amino acid methyl esters, and the D-forms have physical properties identical to those of L-forms except for their optical activity. To examine the chiral specificity of receptors in male $P$. anxia antennae and identify the chirality of the natural components, all of the possible enantiomers were synthesized individually. Chromatography on chiral capillary columns and electroantennographic detection analyses were employed.

Significantly different GC-EAD responses from D- and L-stereoisomers were observed with 20-ng dosages on the male antenna. Synthetic L-valine methyl ester $\left(t_{\mathrm{R}}=9.78 \mathrm{~min}\right)$ elicited strong antennal responses, whereas the D-enantiomer $\left(t_{\mathrm{R}}=9.64 \mathrm{~min}\right)$ was EAD inactive (Figure 2). Interestingly, D-isoleucine methyl ester $\left(t_{\mathrm{R}}=15.12 \mathrm{~min}\right)$ and D-allo-isoleucine methyl ester $\left(t_{\mathrm{R}}=14.92\right.$ min) diastereomers were EAD inactive, but both L-isoleucine methyl ester $\left(t_{\mathrm{R}}\right.$ $=15.40 \mathrm{~min})$ and $\mathrm{L}$-allo-isoleucine methyl ester $\left(t_{\mathrm{R}}=14.74 \mathrm{~min}\right)$ diastereomers elicited equally high EAD responses (Figure 3). Additionally, even though the D-isomers in valine and isoleucine methyl esters elicited no EAD activity, they appeared to affect the EAD responses of the L-isomers negatively when eluting just prior to those isomers (Figures 2 and 3 ).

Results of the chiral capillary resolution experiments with female-gland extracts were consistent with chiral specificity for synthetic valine and isoleucine methyl esters by GC-EAD. The natural components exhibited retention times identical to those of authentic $\mathrm{L}$-valine and $\mathrm{L}$-isoleucine methyl esters on a $\beta$-DEX 120 fused silica chiral capillary column (Figure 4). The possible trace presence of other stereoisomers was beyond the limits of FID detection.

In field experiments conducted in Massachusetts, traps baited with a $3: 1$ blend of L-valine and L-isoleucine methyl esters at three dosages $(1,3$, and 10 $\mathrm{mg}$ ) on rubber septa proved to be attractive (Table 1). The composition of our 


\section{EAD}
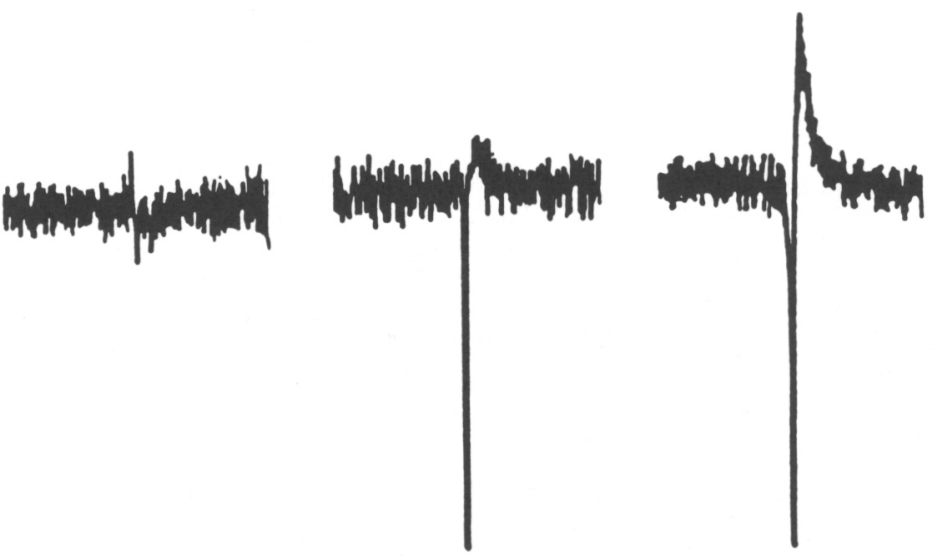

d

S

d d

FID
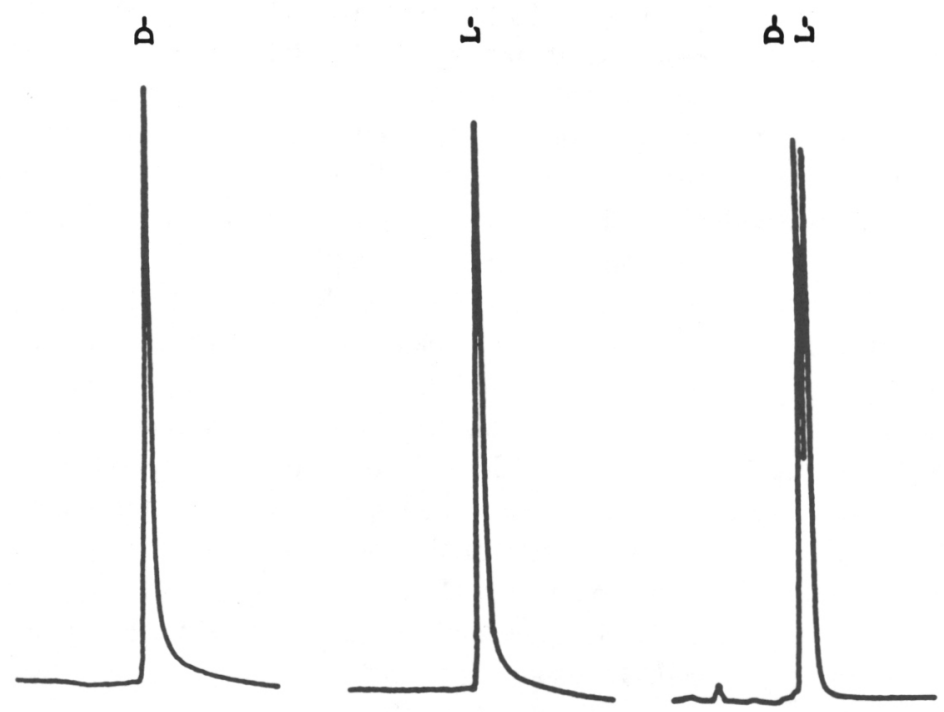

FIG. 2. Partial, reconstructed simultaneous responses from FID and EAG detection using an antenna of male $P$. anxia to synthetic D, L, and DL-valine methyl esters, respectively, on a $\beta$-DEX 120 chiral capillary column.

synthetic valine methyl ester was estimated to be $10 \% \mathrm{D}$ - and $90 \%$ L-isomer. Synthetic L-isoleucine methyl ester contained about $3 \%$ D-isomer. A total of 1114 male $P$. anxia was caught from the two locations during the 1995 season (May 8 to July 14) (Table 1). It was found that there was a significant difference 

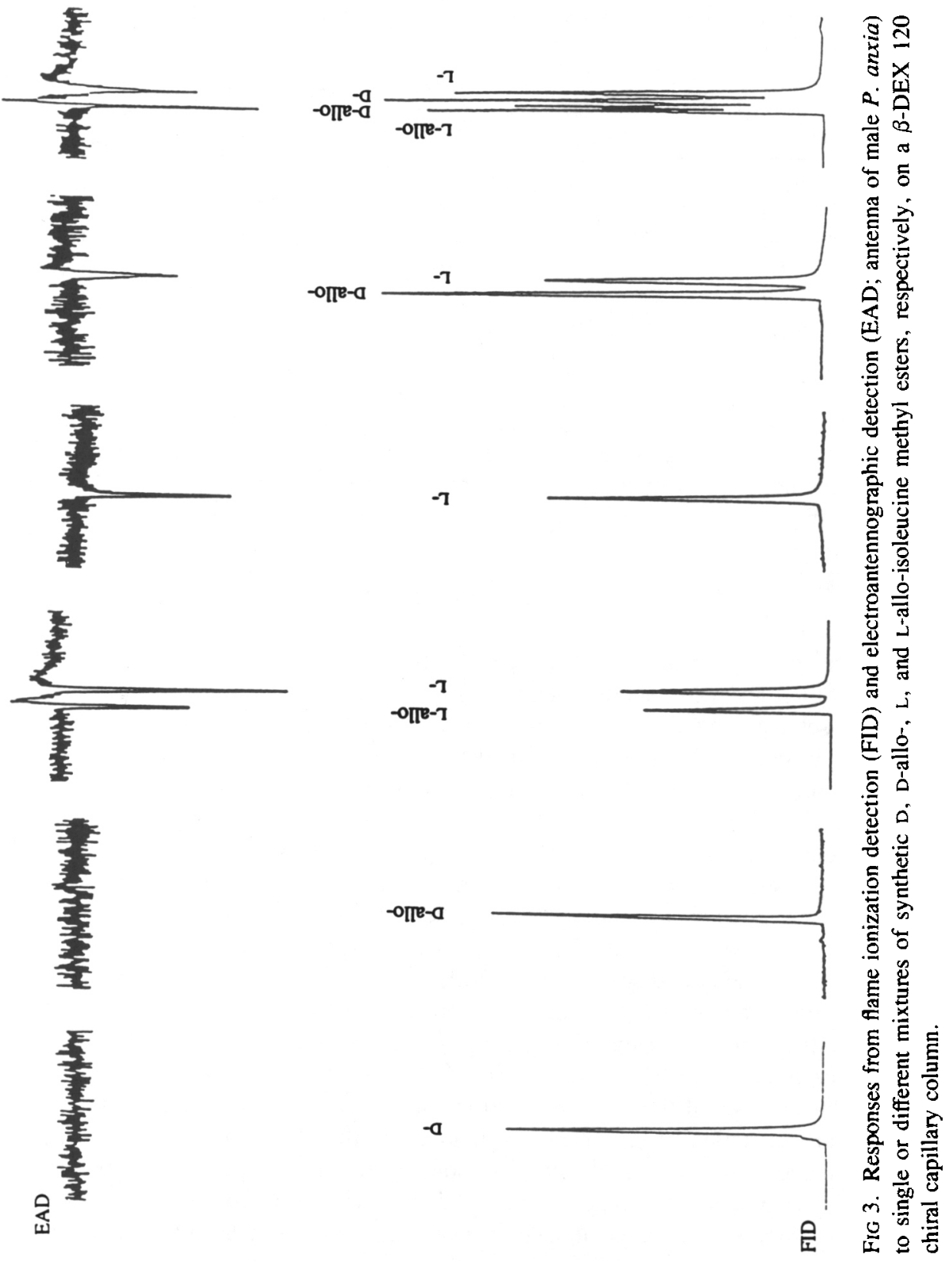
Table 1. Captures of Phyllophaga Males in Traps Baited with a $3: 1$ Blend of L-Valine ANd L-Isoleucine Methyl. Esters on a Rubber Septum ${ }^{a}$

\begin{tabular}{lccrr}
\hline & \multicolumn{4}{c}{ Number of male beetles caught } \\
\cline { 2 - 5 } Location & $0 \mathrm{mg}$ & $1 \mathrm{mg}$ & $3 \mathrm{mg}$ & $10 \mathrm{mg}$ \\
\hline Massachusetts & & & & \\
Terrill & 0 & 34 & 44 & 18 \\
Cranebrook & 1 & 279 & 315 & 423 \\
$\quad$ Total & 1 & 313 & 359 & 441 \\
& & & & \\
\hline
\end{tabular}

${ }^{a}$ Test conducted May 15-July 14, 1995.

in trap catch between control (hexane alone, $0 \mathrm{mg}$ pheromone) and pheromone traps at all dosages, whereas there were no significant differences in trap catch between the three dosages at each of the two locations (one-way ANOVA, $P=0.05$ ).

\section{DISCUSSION}

Our results indicate that the major sex pheromone components of $P$. anxia are L-valine and L-isoleucine methyl esters at a 3:1 ratio. Authentic L-valine and L-isoleucine methyl esters synthesized in our laboratory were active in both electrophysiological experiments and field trapping tests. This apparently represents the first report of chemical communication in the Phyllophaga.

In flight tunnel tests the activation responses exhibited by males to the pheromone (females, female airborne extract, or synthetic blend) were similar to that of another beetle, the oriental beetle (Zhang et al., 1994), but none flew to the pheromone source. Insufficient numbers of males restricted further investigation in the wind tunnel. The age of males, light intensity in scotophase, temperature, and humidity could be important factors influencing oriented flight.

In field-trapping experiments, most of the male beetles were caught in the early part of June. Although dosages of 1, 3, and $10 \mathrm{mg}$ were tested, the 1-mg lure was sufficient to trap male $P$ anxia.

Our analysis of the $P$. anxia pheromone system also showed evidence of seasonal production of the pheromone. Females that emerged from pupae in August and September could not be induced to produce pheromone before undergoing a winter chilling period, as determined by GC-EAD analysis of airborne samples. In March females began producing up to $60 \mathrm{ng}$ of $\mathrm{L}$-valine methyl ester/gland. In contrast, during this entire period electrophysiological activity in male antennae remained the same. 

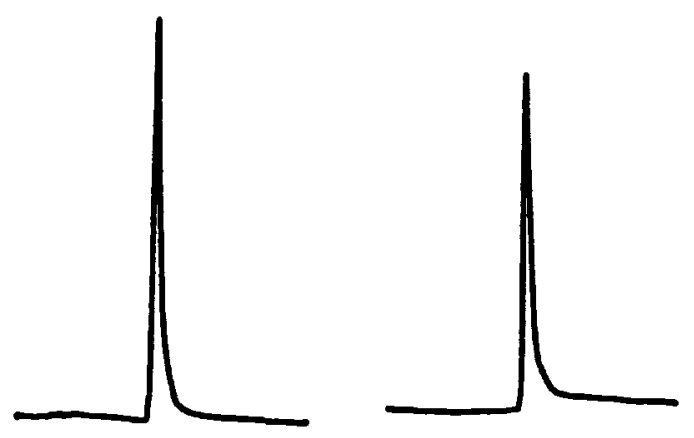

A

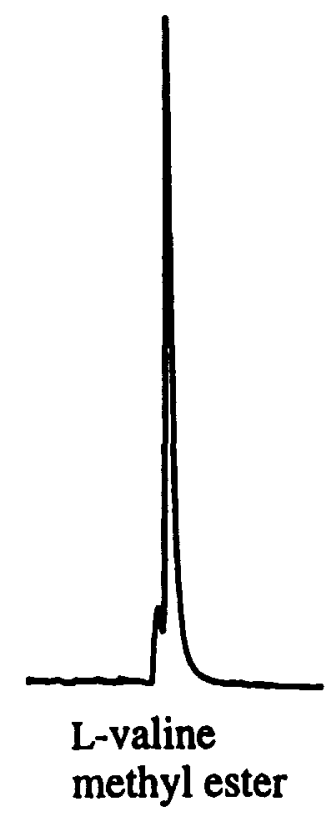

B

FIG. 4. A partial, reconstructed gas chromatogram (FID) of natural pheromone (A) and synthetic L-valine and L-isoleucine methyl esters on a capillary chiral $\beta$-DEX 120 column.

Amino acids are the building blocks from which all proteins are made. With the exception of glycine, the $\alpha$-carbon of all 20 common amino acids is chiral, and at least two enantiomeric forms are possible. However, only the $S$-enantiomers, usually referred to as L-amino acids, are naturally used to construct proteins. Valine and isoleucine are listed as essential amino acids for insects (Hagen et al., 1984), and females obtain them from their food as the 
precursors to synthesize the sex pheromone. The biosynthetic pathway is unknown but may be similar to that found in humans, in which amino acids are methylated by a methyl transferase that uses $S$-adenosylmethionine as the active methyl group donor and reversed by a specific esterase that uses water as the methyl group acceptor. If true, methylation of amino acids would represent one of the simplest sex pheromone biosynthetic pathways for insects.

The stereoselectivity of olfactory cells in $P$. anxia was clearly demonstrated in our chiral-capillary GC-EAD experiments. Only L-isomers elicited EAD responses and all of the D-isomers were electrophysiologically inactive, suggesting that these insect receptors are chiral selective. Female $P$. anxia produces only single enantiomers, L-valine and L-isoleucine methyl esters, as the major sex pheromone components. Therefore, less active or inactive EAG and behavioral responses from their antipodes would be expected (Silverstein, 1988). The D-form amino acid methyl esters may not be synthesized by these insects because their precursors are absent from nature. Electrophyiologically inactive results were obtained from all of the D-forms, D-valine, D-isoleucine, and D-allo-isoleucine methyl esters, in the GC-EAD experiments (Figures 2 and 3). Why the D-forms affect the EAG responses of the L-isomers is unknown. L- and L-alloisoleucine methyl esters elicited the same EAD responses. This indicates that in this species the receptors specify only the amine-attached chiral center and ignore the chirality of second chiral center. Neither attractancy nor antagonism with the L-allo-isomer was formed.

Although no study of EAD responses to the chirality of valine and isoleucine methyl esters has been reported previously, L-isoleucine methyl ester was found in the large black chafer Holotrichia parallela (Mots.) as a sex pheromone component (Leal, 1992). Chirality was not essential for activity, as males ignored antipodes and diastereomers and responded equally well to pure L-isoleucine methyl ester and DL mixtures (Matsuyama et al., 1993), but no data for behavioral responses to L-allo-isoleucine methyl ester with that species were obtained.

In additional preliminary studies with other species we found that $P$. hirticula (Knoch), $P$. futilis (LeConte), and $P$. crassissima (Blanchard) also exhibited high GC-EAD responses to L-valine and L-isoleucine methyl esters. Three other species, $P$. fusca (Froelich), $P$. fraterna (Harris), and $P$. forsteri (Burmeister), were field-trapped in New Jersey with $P$. anxia synthetic pheromone lures during the 1995 season, suggesting that the mating communication system in the Phyllophaga genus involves some components in common, but probably additional components in a blend are needed for specificity. Identification of the three additional minor components in $P$. anxia volatiles could provide a speciesspecific lure for $P$. anxia. A lure compound of the L-valine and L-isoleucine methyl esters could be useful for monitoring a number of Phyllophaga spp. populations. 
Acknowledgments-This research was supported in part by NEIPM Grant 94-34103-0126 and funding from Oceanspray and Cape Cod Cranberry Growers Association. Technical support and advice were provided by Dr. Anne Averill of the University of Massachusetts Cranberry Experiment Station in East Wareham, Massachusetts. Thanks go to Jessica Dunn and Martha Averill, also of the Cranberry Experiment Station, for maintaining the field traps during this study and contributing to the major efforts required for collecting adults and larvae from the bog soil.

\section{REFERENCES}

BjostaD, L. B., and RoELofs, W. L. 1980. An inexpensive electronic device for measuring electroantennogram response to sex pheromone components with a voltmeter. Phys. Entomol. 5:309-314.

Brenner, M., and Huber, W. 1953. Preparation of $\alpha$-amino acids esters by alcoholysis of the methyl esters. Helv. Chim. Acta 36:1109-1115.

FrankLIN, H. J. 1950. Cranberry Insects in Massachusetts. University of Massachusetts, Amherst, pp. $48-50$.

Hagen, K. S., DadD, R. H., and Reese, J. 1984. The food of insects, pp. 79-112, in C. B. Huffaker and R. L. Rabb (eds.). Ecological Entomology. John Wiley \& Sons, New York.

LEAL, W. S. 1992. An amino acid derivative as the sex pheromone of a scara beetle. Naturwissenschaften 79:184-185.

Leal, W. S., Mochizuki, F., Wakkamura, S., and Yasuda, T. 1992. Electroanntennographic detection of Anomala cuprea Hope (Coleoptera: Scarabaeidae) sex pheromone. Appl. Entomol. Zool. 27:289-291.

Matsuyama, S., Leal, W. S., Hasegawa, M., and Sawada, M. 1992. Is chirality essential for pheromonal activity of scarab beetles? The case of the large black chafer, $H$. parallela. Proceedings, 38th Annual Meeting of the Japan Society for Bioscience, Biotechnology, and Agrochemistry.

Mayer, M. S., and McLaughlin, J. R. 1991. Handbook of Insect Pheromones and Sex Attractants. CRC Press, Boca Raton, FL.

Metacalf, C. L., Flint, W. P., and Metcalf, R. L. 1951. Destructive and Useful Insects, 3rd ed. McGraw-Hill, New York.

Ritcher, P. O. 1966. White Grubs and Their Allies. Oregon State University Press, Corvallis, pp. $7-88$

RoELOFS, W. L. 1984. Electroanntennogram assays: Rapid and convenient screening procedures for pheromones, pp. 131-159, in H. E. Hummel and T. A. Miller (eds.). Techniques in Pheromone Research. Springer-Verlag, New York.

Silverstein, R. M. 1988. Chirality in insect communication. J. Chem. Ecol. 14:1981-2004.

TASHIRo, H. 1987. Turfgrass Insects of the United States and Canada. Comell University Press, Ithaca, NY, pp. 109-192.

Westcott, C. 1964. The Gardener's Bug Book, 3rd ed. Doubleday \& Co., New York.

Zhang, A., Facundo, H. T., Robbin, P. S., Charles, E., Linn, J., Hanula, J. L., Villani, M. G., and RoELoFs, W. L. 1994. Identification and synthesis of female sex pheromone of oriental beetle, Anomala orientalis (Coleoptera: Scarabaeidae). J. Chem. Ecol. 20:2514-2427. 